\title{
Synthesis and characterization of the titanium doped nanostructural $\mathrm{V}_{2} \mathrm{O}_{5}$
}

\author{
G. N. Kryukova ${ }^{a}$, G. A. Zenkovets ${ }^{\underline{a}}$, N. Pfänder ${ }^{\underline{b}}$, D. -S. Su ${ }^{\underline{b}}$ and R. Schlögl ${ }^{\underline{b}}$ \\ ${ }^{a}$ Boreskov Institute of Catalysis, pr. Ak. Lavrentieva 5, Novosibirsk 630090, Russia \\ ${ }^{\mathrm{b}}$ Fritz-Haber-Institut der MPG, Faradayweg, 4-6, D-14195, Berlin, Germany
}

Corresponding author.email: kryu@catalysis.nsk.su

\begin{abstract}
Using scanning and analytical transmission electron microscopies (TEM), the morphology and structure of nanostructurally assembled $\mathrm{V}_{2} \mathrm{O}_{5}$ doped with Ti has been studied. It was found that the bulk structure of the oxide particles crystallized in rod-like shape is of the $\mathrm{V}_{2} \mathrm{O}_{5}$ type whereas Ti atoms are located mainly on the thin surface layer of the rods. Such surface coating is nonuniform and contains up to 3 at.\% of titanium. Modification of the oxide sample with titanium atoms seems to stabilize the $\mathrm{V}_{2} \mathrm{O}_{5}$ structure against electron beam irradiation.
\end{abstract}

Keywords: HREM; EDX; $V_{2} \mathrm{O}_{5}$; Nanorod; Catalyst

\section{Introduction}

Owing to the wide use of vanadium pentoxide as catalysts for some reactions of mild oxidation [ 1 and $2]$, as gas sensors and reversible cathodes in lithium and magnesium batteries [ $\underline{3}$ and 4$]$ this material attracts the attention of many researchers. In the field of selective oxidation catalysis, vanadium pentoxide is believed to play an important role for the adsorption of oxygen and for its further transfer to the organic substrates though different models proposed for these mechanisms are contradictory. Continued search for new oxides which could be used as cathodic materials for advanced lithium batteries resulted in metastable vanadium oxides as good candidates. Those metastable structures and possibly the addition of a second metal might be critical in obtaining reversible lithium intercalation. Study of the reasons for the unique chemical and electronic properties of $\mathrm{V}_{2} \mathrm{O}_{5}$ is still under way especially in the case of doping the oxide with some other elements that may result in changes of morphology, structural arrangement and electronic parameters [5] of this material. Another aspect of $\mathrm{V}_{2} \mathrm{O}_{5}$ doped with foreign atoms is also important; small amounts of solutes may affect strongly the reactivity of this oxide. Furthermore the way by which dopants can be introduced into the structure of the parent oxide is of interest. The use of novel techniques, like nanostructural assembling, allows new materials, often with open structures, to be obtained that are often not able to be synthesized by conventional preparation routes. Therefore, we used a special procedure for the synthesis of titaniumdoped $\mathrm{V}_{2} \mathrm{O}_{5}$. This paper summarizes our work on these topics. 


\section{Experimental}

The sample was prepared by a spray-drying of the mixture of vanadyl oxalate solution with anatase $\left(\mathrm{TiO}_{2}\right)$ followed by the air calcination of the powder obtained at $500{ }^{\circ} \mathrm{C}$ for $2 \mathrm{~h}$. Concentration of $\mathrm{TiO}_{2}$ in the parent mixture was equal to $6 \mathrm{wt} . \%$.

X-ray powder diffraction (XRD) was used to determine the phase composition of the sample. XRD patterns were recorded using URD-6 diffractometer $\left(\mathrm{Cu}-\mathrm{K}_{\alpha}\right.$ radiation, graphite monochromator on the reflected beam).

The morphology of $\mathrm{Ti}$ doped vanadia nanoparticles was determined by scanning electron microscopy (SEM) (REM-100U microscope operated at $30 \mathrm{kV}$ ). For SEM analysis, the sample was put onto a copper grid and gold sputtered in the Coating System VUP4.

Transmission electron microscopic (TEM) and high resolution transmission electron microscopic (HREM) images were obtained with Philips CM-200 transmission electron microscope at the resolution of $0.20 \mathrm{~nm}$. Elemental analysis was carried out using the same machine fitted with an EDAX DX-4 microanalysis system with an energy-dispersive spectrometer (EDX). For study, sample was crushed in an ethanol slurry, and the resulting solution was dispersed on the holey-carbon films mounted on the copper grids.

\section{Results and discussion}

According to XRD analysis the phase composition of the sample was identified as pure $\mathrm{V}_{2} \mathrm{O}_{5}$ (space group Pmmn; an orthorhombic cell; lattice constants $a=1.1516(4), c=0.43727(4) \mathrm{nm}$ ) [] $]$. There were no peaks assigned to the titanium metallic or oxidic phases in the XRD pattern of the sample. Titania nanocrystals were not observed also; at the same time, electron microscopy indicated on the specific morphology of the nanostructural oxide particles. The most striking observation was that they are crystallized in the irregular shape of a thin rods of some micrometers in length and $10 \mathrm{~nm}$ in thickness. $\mathrm{V}_{2} \mathrm{O}_{5}$ crystals obtained by a conventional route, via thermal decomposition of the vanadyl oxalate, have a different shape - they are usually long platelets not needles. SEM Fig. 1a clearly shows that specimen particles are tubularly shaped, typically $40 \mathrm{~nm}$ in external diameter, though rods with a smaller diameter are also observed. Typical TEM micrograph of the rod-like $\mathrm{V}_{2} \mathrm{O}_{5}$ microcrystal is shown in Fig. 1b where extended oxide nanocrystals are clearly visible. Selected area electron diffraction pattern given in the insert of Fig. $1 \mathrm{~b}$ confirms that $b$ axis is a long axis of the oxide nanoparticle.

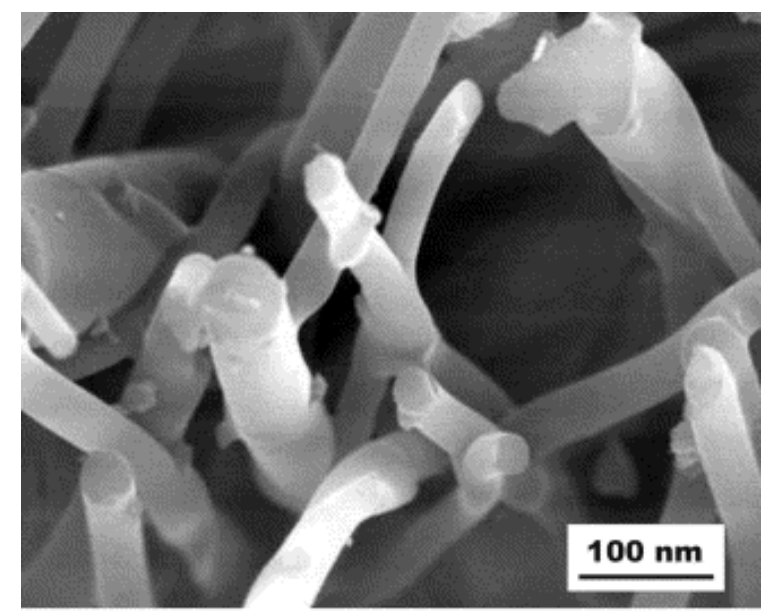

(a)

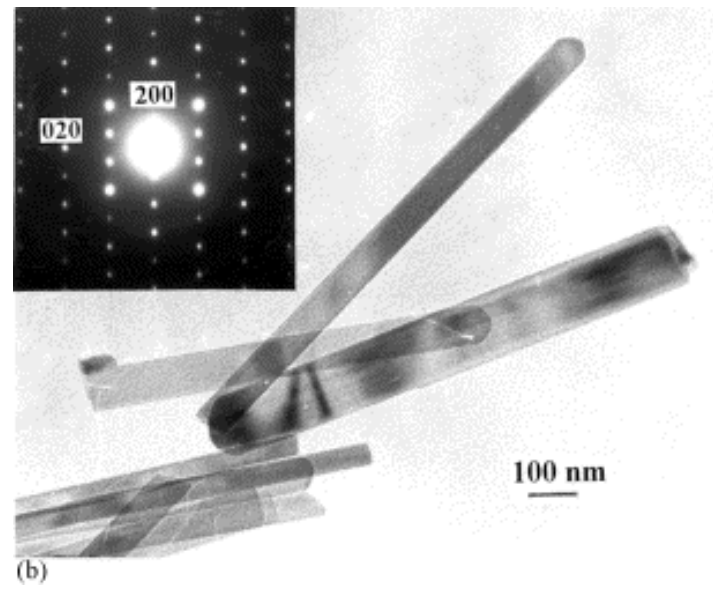

(b)

Fig. 1. SEM micrograph (a) and TEM micrograph (b) of Ti doped vanadia rod with selected area electron diffraction pattern of this material given in the inset of (b). 
Other interesting peculiarity of this material was its relatively high stability upon electron beam irradiation: we did not observe any transformation of the sample structure, such as hole drilling or phase transition of $\mathrm{V}_{2} \mathrm{O}_{5}$ into more reduced form, $\mathrm{V}_{2} \mathrm{O}_{4}$, for at least $15 \mathrm{~min}$. At the same time, many authors claimed that examination of the $\mathrm{V}_{2} \mathrm{O}_{5}$ structure in the electron microscope is practically impossible due to the strong electron beam damage (see, for example, references $[\underline{7}$ and $\underline{8}]$ ). High stability of the nanostructural vanadia enabled us to conduct HREM study and to get EDX spectra from the different parts of rod-like oxide nanocrystals.

Fig. 2 shows HREM image of the structure of oxide nanocrystal. It is clearly seen (area marked with A in Fig. 2) that some spots are arranged in the regular rhombohedral motif. Spots in the other region (marked with B in Fig. 2) are not so well ordered, and the structure looks highly distorted. It should be noted that similar imperfect structure is visible in the thin layer closely related to the surface of vanadia rod. These areas are marked with arrows in the micrograph. Note that structure in the disordered areas looks rather sharp, not diffuse or faint. We [ $\underline{8}]$ observed the transformation of the sharp 110-lattice fringes of pure $\mathrm{V}_{2} \mathrm{O}_{5}$ into faint and diffuse fringes simultaneously with a change of their spacing when studying the effect of the radiation damage on the structure of vanadium pentoxide. These transformations took place after $10 \mathrm{~min}$ of the oxide irradiation by electron beam in the electron microscope column. In the case of vanadia nanorods exposure of the sample to the incident electron beam for relatively long time (about $30 \mathrm{~min}$ ) does not give rise to similar structure evolution, and the structure looks nonuniform along the length of the nanorod-regions of perfect lattice matching are alternated with areas possessing high lattice disorder. Therefore, areas with imperfect arrangement observed in the nanorod structure could not be considered as a result of the radiation damage.



Fig. 2. High resolution TEM image of the structure of Ti doped $\mathrm{V}_{2} \mathrm{O}_{5}$ nanocrystal viewed along the [001] direction. Areas of the regular and imperfect structure are indicated by A and B, respectively (see details in the text).

The quantitative EDX measurements of the vanadia rods reveal that their structure is Ti enriched. Fig. $\underline{3}$ a, b show typical EDX spectra acquired from the crystal region with a regular structural motif and area of nanorod with imperfect structure, respectively (note that $\mathrm{Cu}-\mathrm{K}_{\alpha}$ and $\beta$ peaks are due to the copper grid onto which the sample was replaced). The spectrum given in Fig. $3 \mathrm{a}$ indicates that the former area is composed of $\mathrm{V}$ and $\mathrm{O}$ and no Ti is detected, whereas the spectrum shown in Fig. $3 \mathrm{~b}$ demonstrates the existence of $\mathrm{V}, \mathrm{O}$ and $\mathrm{Ti}$ elements in the crystal areas possessing disordered structure. In this case Ti content is as big as 3.3 at.\%. Sometimes EDX spectra obtained show the titanium concentration lying in between these values, since areas with imperfect structure appear at random over the whole length of the nanorod, as evident from HREM data. But in any case, when we got EDX spectra from different parts of the nanorod, bigger titanium content has been registered in the particle regions with a higher degree of structural disorder than a regular ones. Taking into account these data and fact of the partially disordering of the structure of vanadium oxide we suggested that $\mathrm{Ti}$ atoms are incorporated in the surface layer of the oxide nanocrystal that gives rise to the distortion of 
$\mathrm{V}_{2} \mathrm{O}_{5}$ structure in this place. We could not consider that rods have a sandwich structure with Tienriched layer at their periphery. More likely that Ti-doped areas appear as isolated islands on the outer surface of the rods without formation of continuous and uniform coating of the oxide particles since Ti-K $\mathrm{K}_{\alpha}$ peaks in EDX spectra acquired from different parts of the rod are nonequal by intensity. Outer layers containing Ti atoms is rather thin (about $2 \mathrm{~nm}$ ) as evident from HREM micrograph (Fig. 2) which exhibits the presence of areas with either perfect or defect oxide structure in the plane view.

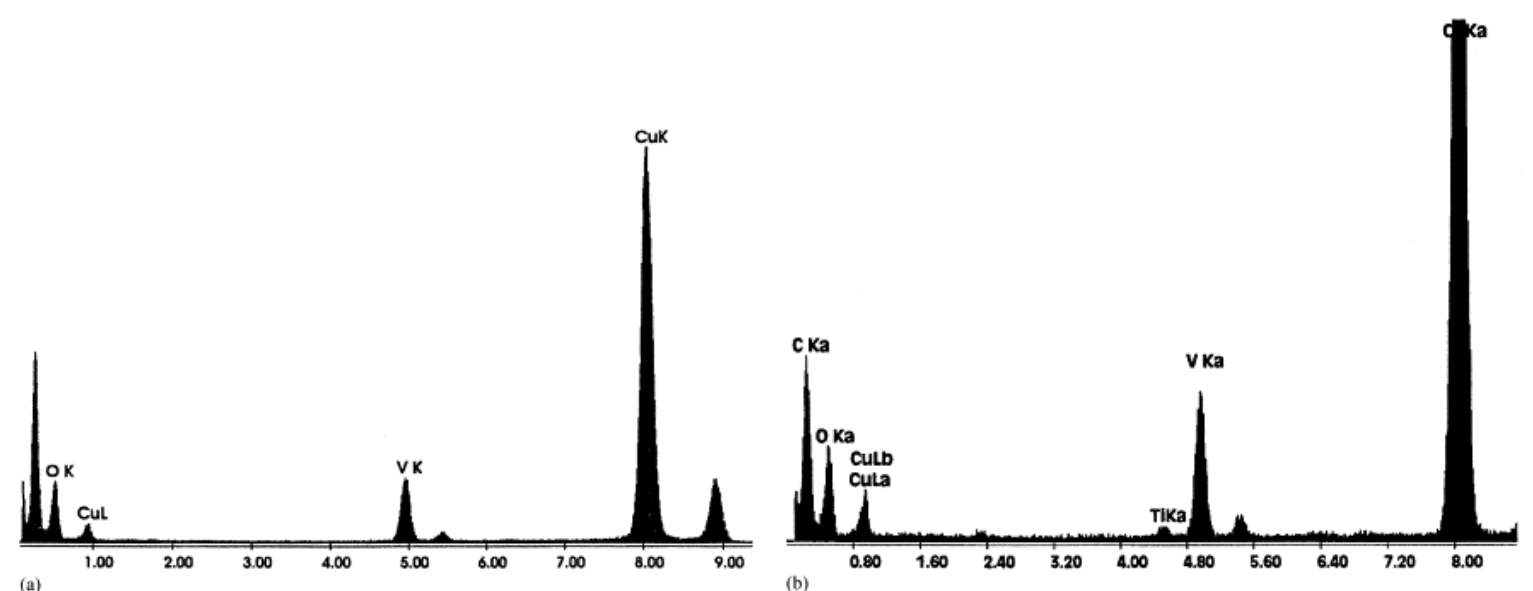

Fig. 3. TEM/EDX spectra acquired from the part of vanadia nanocrystal with perfect lattice (a) and from the particle area with distorted structure (b).

We would like to emphasize that this microstructural arrangement of the oxide nanocrystal remains stable upon the electron beam irradiation. Transformation of $\mathrm{V}_{2} \mathrm{O}_{5}$ into more reduced $\mathrm{VO}_{2}$ form takes about 35 min under HREM observation comparing with 2 min characteristic for the conventional vanadium pentoxide. To understand a reason for this phenomenon, let us recall that the structure of $\mathrm{V}_{2} \mathrm{O}_{5}$ is built up from distorted $\left[\mathrm{VO}_{6}\right]$ octahedra sharing edges and corners that form $\mathrm{V}_{2} \mathrm{O}_{5}$ slabs. Latters are linked together through weak V---O bonds parallel to $c$ direction of the oxide unit cell [9] and, formally, this structure may be considered as composed of layers. To increase the threedimensional character of this phase some guest atoms, such as $\mathrm{Fe}[\underline{10}], \mathrm{Cr}[\underline{11}]$ or $\mathrm{Mg}$ [12], may be replaced into interlayer positions along $c$ axis of the host oxide thus forming $\mathrm{MeO}_{6}$ short chains linking the $\mathrm{V}_{2} \mathrm{O}_{5}$ layers. The structural motif of the host lattice does not change though over $10 \mathrm{wt} . \%$ of the dopants can be accepted by the lattice that gives a structural formula of $\mathrm{Me}_{0.11} \mathrm{~V}_{2} \mathrm{O}_{5.16}$ and results in a high stability of the oxide phase. But one can hardly expect such a situation for our sample, since the concentration of $\mathrm{Ti}$ atoms is too low to form the intercalated vanadium oxide with an admixture atoms situated in between the $\mathrm{V}_{2} \mathrm{O}_{5}$ layers. Besides, as evident from HREM and EDX data, Ti atoms locate mainly on the surface or in the subsurface layer of vanadia particles and distribution of Ti over $\mathrm{V}_{2} \mathrm{O}_{5}$ nanocrystals is rather nonuniform. Recently, we synthesized and studied nanostructured vanadiabased catalyst with $\mathrm{V}_{2} \mathrm{O}_{5}$ loading as high as 5 wt.\% [13]. Main structural feature of this system is a nanometer sized $\mathrm{V}_{2} \mathrm{O}_{5}$ species which are situated on the surface of anatase nanocrystal and form an interface with the latter. This catalyst shows good activity and selectivity in the reaction of $\beta$-picoline oxidation [14] and reaction of selective reduction of NO with ammonia [15]. It seems likely that a reason for its excellent behavior is a presence of the interface being a mixed layer composed of vanadium, oxygen and titanium atoms with a possible appearance of $\mathrm{V}---\mathrm{O}---\mathrm{Ti}$ bonds. It is important that this catalyst did not demonstrate effect of the structural transformation of anatase into rutile, so characteristic for the monolayer vanadia catalysts [16], even upon the strong reducing conditions, and the presence of the interface is highly believed to supress a possibility of such phase transition. In the case of titanium doped vanadia rods titanium atoms appear at random on the surface of $\mathrm{V}_{2} \mathrm{O}_{5}$. There is no clear evidence whether they might occupy the positions within the $\mathrm{V}_{2} \mathrm{O}_{5}$ layers and/or in between them. But the thickness of the distorted layer on the surface of the rod is rather small (about $2 \mathrm{~nm}$ ) therefore, it is more probable that titanium atoms are exchanged for vanadium atoms situated in the regular cation positions of vanadia slabs instead of the interlayer sites. We suggest that some Ti---O--- 
$\mathrm{V}$ bonds occur in the surface layer that, as in the case of nanostructured vanadia-titania catalyst, might contribute to the stability of this system.

Further experiments on the electronic properties of this material are underway. We have yet to obtain also more information concerning the catalytic activity of the material prepared as well as to understand whether vanadium atoms in the structure of nanorods can be substituted by different cations such as iron or cobalt aiming at a modification of mechanical, electrical and catalytic properties of the vanadia nanorods.

\section{Conclusion}

Using nanotechnology, novel $\mathrm{V}_{2} \mathrm{O}_{5}$ oxide doped with Ti atoms has been synthesized. SEM and TEM revealed that vanadia particles are crystallized in the form of thin rods, and small (about 3 at.\%) amount of titanium atoms is spread out nonuniformly over the surface of oxide nanocrystals thus forming an imperfect subsurface layer. This material demonstrates unusual stability upon electron beam: the transformation of $\mathrm{V}_{2} \mathrm{O}_{5}$ structure into more reduced, $\mathrm{V}_{2} \mathrm{O}_{4}$ oxide and process of hole drilling both typical for the observation of vanadium pentoxide structure in the electron microscope column were not registered. Reason for this unusual stability is likely to steam from the modification of the $\mathrm{V}_{2} \mathrm{O}_{5}$ structure with titanium atoms.

\section{Acknowledgements}

G.N. Kryukova is deeply indebted to the Max-Plank-Gesellschaft for the financial support 


\section{References}

1. J.C. Otamiri and A. Andersson Catal. Today 3 (1988), p. 211.

2. A. Andersson, J.-O. Bovin and P. Walter J. Catal. 98 (1986), p. 204.

3. J.-P. Pereira-Ramos, N. Baffier and G. Pistoia In: G. Pistoia, Editor, Lithium Batteries, New Materials, Developments and Perspectives, Independent Chemical Library 5, Elsevier, Amsterdam (1994), p. 281.

4. P. Novak and J. Desilvestro J. Electrochem. Soc. 140 (1993), p. 140.

5. J. Haber, M. Witko and R. Tokarz Appl. Catal. A 157 (1997), p. 3.

6. JCPDS data file no. 41-1426.

7. A. Vejux and P. Courtine J. Solid State Chem. 63 (1986), p. 179

8. D.S. Su, M. Wieske, E. Beckmann, A. Blume, G. Mestl and R. Schloegl Catal. Lett. 75 (2001), p. 81

9. R. Enjalbert and J. Galy Acta Crystallogr., Sect. A 142 (1986), p. 1467

10. S. Maingot, P. Deniard, N. Baffier, J.P. Pereira-Ramos, A. Kahn-Harari, R. Brec and P. Willmann J. Power Sources 54 (1995), p. 342.

11. G. Gregoire, N. Baffier, A. Kahn-Harari and J.-C. Badot J. Mater. Chem. 8 (1998), p. 2103.

12. G.V. Shklover, T. Haibach, F. Ried, R. Nesper and P. Novak J. Solid State Chem. 123 (1996), p. 317.

13. G.N. Kryukova, D.O. Klenov and G.A. Zenkovets React. Kinet. Catal. Lett. 60 (1997), p. 179.

14. E.M. Al'kaeva, T.V. Andrushkevich, G.A. Zenkovets, G.N. Kryukova and S.V. Tsybulya Catal. Today 61 (2000), p. 249.

15. G.A. Zenkovets, G.N. Kryukova, Z. Sobalik, S.V. Tsybulya, V.N. Parmon, Proceedings of the Fourth World Congress on Oxidation Catalysis, Berlin/Potsdam, Germany, September 16-21, 2001, Dechema, Frankfurt am Main, 2001, v. 2, p. 225.

16. G. Oliveri, G. Ramis and G. Busca J. Mater. Chem. 3 (1993), p. 1239. 